\title{
A STUDY OF ATTITUDES TOWARD LEARNING ENGLISH AT AN EARLY AGE BY TAIWANESE PARENTS WITH YOUNG CHILDREN
}

\author{
Hung-Chung Lee and Mei-Ju Chou \\ Department of Early Childhood Education, Taiwan Shoufu University, Taiwan, R.O.C
}

Received 2014-03-01; Revised 2014-03-04; Accepted 2014-03-19

\begin{abstract}
This study aims to investigate the parental attitudes towards young children's learning English in kindergarten at an early age. The subjects of the research survey are comprised of 189,792 young children enrolled in Taiwan kindergartens as the population. This number underwent stratified random sampling using a ratio of $0.5 \%$, yielding a total of 949 samples. The number of valid questionnaires recovered was 709 and the valid response rate was $76.2 \%$. The results of the subsequent analysis of the data are indicated as follows: Parents living in central and northern Taiwan with educational backgrounds of graduate school or higher tend to disagree in their attitudes towards young children learning English at an early age as compared to the attitudes of parents living in southern Taiwan with high school degrees. Parents agreeing more with secular parenting concepts tend to concur more in their attitudes towards young children learning English at an early age. The views of parents living in various regions with different educational backgrounds towards young children learning English at an early age are primarily affected by their views on secular parenting concepts. Specific research implications of these findings are discussed in the latter part of this article.
\end{abstract}

Keywords: Parents of Young Children, Learning English at an Early Age, Learning English

\section{INTRODUCTION}

The increasing significance of mastering English seems to have encouraged more primary schools to include this subject in their curriculum. "Don't let your children lose out at the starting point." is one of the popular slogans quoted related to Taiwan's English education. The reason why parents hold this belief is moderately because of traditional Chinese culture and partially due to modern knowledge globalization. Parents are so worried whether their children are able keep pace in the academic learning area, especially for the subject of English, which is an international language which brings about significant influence in children's learning motivation and learning efficiency. The notion of when it comes to English learning, the younger the better, is widely accepted by the Taiwanese people (Wang and Chang, 2011; Birdsong and Molis, 2001).
As a consequence, Taiwanese children are compelled to be taught English as early as possible. In 2004, Taiwan's Ministry of Education mandated that all public elementary schools should begin teaching English courses from Grade 3 but the majority of schools start teaching English in the first grade. Some private language schools even offer all-English programs for toddlers starting from one-year-old. Thus, a trend can be seen where both the public and private sectors expect that English should be taught at an early age (Tsai, 2001).

As English learning has become popular in Taiwan, many parents are sending their young children to English language schools or bilingual kindergartens offering courses in Chinese and English. These parents may be anxious that their children might fall behind their peers in English proficiency because of the famous commercial slogan, "Don't let your children lose at the starting point." It is believed that the earlier you begin to learn a language, the more likely you will master it. Parents, as long as they can

Corresponding Author: Mei-Ju Chou, Department of Early Childhood Education, Taiwan Shoufu University, Taiwan, R.O.C. 
afford the fees, are eager for their children to take English lessons early in life. A survey by Chang et al. (2002) revealed that in Taipei city, $83 \%$ of all sixth graders had taken English courses in their schools and greater than $80 \%$ of elementary school students had participated in English cram schools after school. Moreover, the English learning bandwagon has swept across the country.

Reaffirming views held by the parents are native English-speaking teachers who are basically promising that their Taiwanese students will view the world differently and that proficiency in English will give them a more global perspective. The overarching concepts are that English should be learned at an early age and by doing so; English learning will transform Taiwanese children into "global" individuals (Kuo, 2002).

However, there are numerous studies that contradict the premise of "the earlier, the better." (Brown, 2007) There is abundant evidence to suggest that foreign language learners, who have established a firm foundation in their native language, in this case Chinese, will achieve better results in second language learning. However, in Taiwan there are many over-eager parents who send their children to bilingual kindergartens to study English at a very young age. Influenced by the English learning hype, these parents ignore the possibility that their children might be disadvantaged in the long run for being deprived of building a basic foundation in their first language of Chinese.

Moreover, even when Taiwanese English learners start studying at an early age, they rarely display perfect mastery of English. Age is merely one of many factors that influence an individual's language acqusition. Second language or foreign language learning encompasses many complex learner variables such as student motivation, the student's attitudes towards learning and learning styles. Other variables include aptitude toward learning English, conditions for English teaching/learning as well as the goals of English education. Furthermore, these are all embedded in broader political, social, economic and teaching contexts. It was also found that the students' anxiety level was related to their perception of the status and function of the two languages, to parental influence and to the language environment (Yan and Detaramani, 2008). It is worth investigating these uncertain doubts through analysis of the empirical evidence.

\section{MATERIALS AND METHODS}

\subsection{Children Language Learning}

Children language learning encompasses the following aspects: Active, creative and natural ( $\mathrm{Su}$,
1999). Children are naturally active and creative language pupils. They observe how people around them express themselves; acquire expressions and later produce dissimilar and additional expressions for achieving a communicative goal than what they have heard from others. In short, they are naturally physically active and psychologically creative when they are learning.

The following aspects should be studied when discussing child language learning: Neurological, cognitive and affective (Brown, 2007). The neurological aspect involves lateralization in the brain hemisphere, the biological schedule, the right brain hemisphere participation and the importance of accent (Bowers et al., 2013). As the child matures, brain lateralization takes place, with the left hemisphere controlling the logical, intellectual and analytical functions and the right hemisphere focusing on the social and emotional functions (Azmitia, 2007). Language functions are mainly controlled by the left hemisphere and somewhat by the right hemisphere. Empirical evidence obtained by researchers such as Leneberg indicate that the slow lateralization process begins approximately at the age of two and stops around puberty. Scovel, as cited by Brown (2007), states that brain elasticity before puberty allows children to acquire a foreign language and after puberty it will be more difficult for them to succeed in foreign language learning, especially in the learning of pronunciation.

It is assumed that human accent stabilization occurs during a fixed timetable. The facility in acquiring language varies with different aspects of language learning. In this connection, Guiora et al. (1972) concluded the following: Lower-order processes (including pronunciation) are dependent on early maturing and less adaptive macro neural circuits, which makes foreign accents difficult to overcome after childhood. High-order language functions, such as semantic relations, are more dependent on late maturing neural circuits, which may explain why college students can learn grammar and vocabulary many times more effectively than elementary students can learn at a given period of time (Mayberry et al., 2011).

This conclusion provides evidence on the existence of a neurology-based critical age, especially in the acquisition of pronunciation skills, which is different from communicative fluency and other high-order processes. Referring to Piaget's theory of cognitive development, the critical age of language acquisition in terms of cognitive aspects takes place at puberty, around the age of eleven. It is during this period that one begins to make abstractions and think formally about topics which are transcendental in concrete experiences and direct perceptions. During this time, learners can benefit 
from deductive explanations. It should be noted, that being overly consciousness about the rules will impede the foreign language learning processes (Snow and Hoefnagel-Hohle, 1978).

\subsection{The Influence of Family Background}

Apart from the factors that are related to an early start in English learning, the family background influence, such as parental Socioeconomic Status (SES), parental involvement and parental expectations, are considered to be closely related to English learning. As we know, an early stage of society for one person is the family, which contains fundamental influence on individuals. As for parents acting as the foundation of the family, parents are their children's first and most influential teachers and they play significant roles in the learners' English learning. In this case, various family backgrounds result in the differences of students' learning academic achievement (Molfese et al., 2010).

Kau (1991) pointed out that an individual was greatly influenced by the external environment, like the family. And family is the greatest influence on a child (Rodriguez and Adamsons, 2012). Children's socialization, learning and development depend on the family. Wei and Yang (2010) proposed, based on metaanalysis of studies on learning, that an academically stimulating home environment was one of the major determinants of learning. Wei and Yang (2010) also found from these studies that the average effect of home curriculum on achievement was twice as large as SES. This home curriculum included informal parentchild conversations about everyday events, encouragement and discussion of leisure reading, monitoring expressions of affection and the children's academic and personal growth.

In a study widely known as the Coleman Report, the subjects were 645,000 students located in 4,000 elementary and secondary schools. The study found that schools brought little influence on a child's achievement, while family background was the central explanation for student achievement. In other words, family mattered more than schooling (Coleman et al., 1966).

\subsection{Family Background, Parenting Concepts and Young Children Learning English}

In terms of parental education, parents with high education levels leveraged their abilities to help children with homework and to effectively communicate with teachers (McGillicuddy-DeLisi, 1982; Sigel and McGillicuddy-DeLisi, 2005). Moreover, parental education levels affected the children's education expectations. Parents with higher education levels would hope that their children would have higher achievement and, thus, would pay more attention to their children's achievement (Robinson and Harris, 2013). However, parents with a low education level might have inadequate knowledge that could negatively affect the families' decisions regarding their children's development and learning.

Hwang (1997) noted that only $13 \%$ of children's daily lives were in schools. That is, $87 \%$ of the children's daily lives planning were handled by their parents. What the parents did to assist their children to learn was more critical to academic success than how affluent the family was. According to Jhong (2009), parental involvement in education includes six types: Parenting, communicating, volunteering, learning at home, decision making and collaborating with the community. As far as volunteering, the parents could be resources in the classroom. Parents, as volunteers, could provide additional help, giving extra attention to individual children, accompanying classes in field trips and creating learning materials. Furthermore, the parents' participation in school was a clear sign to children that the parents valued education.

The results of numerous studies revealed that parental involvement had a potential to improve student achievement and behavior (Bourdieu and Passeron, 1990; De Graaf, 1986; Farkas et al., 1990). Those people involved in education realized that working closely with families is essential in improving the students' achievement. Buchmann et al. (2010) indicated that the benefits of parental involvement incorporated higher test scores and grades, better school attendance, greater completion percentage of homework, more positive attitudes and behavior, superior graduation rates and greater enrollment in higher education. The review by Henderson and Berla (1994) covered many resources including 66 studies, reviews and reports on the function and importance of family to a student's education and achievement in school and the community. They found the fundamental influence of parental involvement on students, especially when they were in the time period from being young children to high school students; that is, when parents were involved in their children's education at home, they did better in school.

In the study of social capital, Coleman (1988) proposed a model in which social capital is a resource which an individual can use, along with others such as their own skills and expertise (human capital), tools 
(physical capital), or money (economic capital). This is similar to the educational resource of Teachman (1987). The Coleman report was commonly misinterpreted as evidence that schools have little influence on student achievement. A more valid interpretation of the Coleman Report is that compared to student background and socioeconomic status, differences in school resources are not as critical in determining educational results (Heinesen and Graversen, 2005).

This research also suggests that socially disadvantaged black students benefited from schooling in racially-mixed classroom environments. This was the catalyst for the implementation of the desegregation busing systems, transporting black students to integrated schools. In follow-up to this, in 1975, Coleman published the results of further research. The research focused on documenting the effects of school busing systems intended to bring lower-class black students into higher-class mixed race schools. He observed that some white parents reacted by moving their children out of such schools in large numbers, which is a phenomenon that came to be known as "white flight." In Coleman's 1966 article, he explained that the black students would benefit from integrated schooling if there was a majority of white students in the classroom. From this perspective, the mass busing system had failed to reach its goals (Burchinal et al., 2002). Based on the theoretical and empirical backgrounds, the following hypothesis is derived:

H1: Family background is positively related to attitudes towards young children learning English at an early age

$\mathrm{H} 2$ : Parenting concepts is positively related to attitudes towards young children learning English at an early age

H3: Family background has a positive impact on attitudes towards young children learning English at an early age through the mediating effect of parenting concepts

\subsection{Sampling and Data Collection}

The sample of this study focuses on the parents of kindergarten age children. Questionnaires were distributed to assemble the data in this study. A questionnaire was submitted as a pre-test to verify potential shortcomings in comprehension and to validate its appropriateness. A pilot test of the survey was conducted with 40 parents within one of the kindergartens in the Taipei area. Based on the pre-test results, some revisions on the questionnaire were made. Questionnaires were administered with the sample being randomly selected from 3,283 kindergartens, covering 189,792 young children in Taiwan. Parents of young children from all areas of Taiwan responded to the questionnaire through their own actual experience. The questionnaires finally yielded 931 completed questionnaires. Out of these, 709 were usable and valid for our study.

\subsection{Measurement Tools}

The measurement instrument was designed based on numerous previous studies. All the questionnaire items were measured on a five point Likert scale. Respondents were asked to indicate their level of agreement toward each statement, from 1 (strongly disagree) to 5 (strongly agree).

\subsubsection{Family Background}

The family background in this study includes the parents' role, age, living region and educational background.

\subsubsection{Parenting Concepts}

We used and adjusted the measuring scales. In all, five items were used to test the parenting concepts.

\subsubsection{Attitudes Towards Young Children Learning English at an Early Age}

We use and adjust the measuring scales. In all, two items were used to test the attitudes towards young children learning English at an early age.

\subsection{Purification and Reliability of Measurement Variables}

To purify the measurement scales and to identify their dimensionality, a principal components reliability test with varimax rotation was applied to condense the collected data into certain factors. After the reliability test, we used item-to-total correlation and internal consistency analysis to confirm the reliability of each research factor. The reliability of five latent variables was investigated by calculating Cronbach's alpha. The range of the values was between 0.73 and 0.86 , which indicated that all measures were reliable.

\section{RESULTS}

\subsection{Quantitative Data Analysis}

The results show the typical responses in Table $\mathbf{1}$. 


\subsection{Assumption Tests}

\subsubsection{Family Background and Attitudes Towards Young Children Learning English at an Early Age}

To examine the relationship between the family background and attitudes towards young children learning English at an early age, a one-way ANOVA was applied. From the analysis of ANOVA, we record the results in Table 2. The results reveal that the parents living in central and northern Taiwan with educational backgrounds of graduate school or higher tended to disagree in their attitudes towards young children learning English at an early age as compared to parents living in southern Taiwan with high school degree educational backgrounds.

\subsubsection{Parenting Concepts and Attitudes Towards Young Children Learning English at an Early Age}

To examine the relationship between the parenting concepts and attitudes towards young children learning English at an early age, a one-way ANOVA was applied. From the analysis of ANOVA, we record the results in Table 3. The results reveal that the parents who agree with secular parenting concepts tended to agree more in their attitudes towards young children learning English at an early age.

Table 1. Profile of respondents $(n=709)$

\begin{tabular}{lcc}
\hline & Number of respondents & Percent of respondents $(\%)$ \\
\hline Parents' role & 236 & 33.30 \\
Father & 449 & 63.30 \\
Mother & 24 & 3.40 \\
Others & & 6.90 \\
Parents' age & 49 & 29.20 \\
Under 29 & 207 & 37.10 \\
$30-34$ & 263 & 17.80 \\
$35-39$ & 126 & 9.00 \\
$40-44$ & 64 & 34.60 \\
Over 45 & 245 & 52.00 \\
Educational background & 369 & 13.40 \\
Senior or vocational high school & 95 & 35.10 \\
University or junior college & & 25.80 \\
Masters or higher degree & 249 & 32.70 \\
Living region & 183 & 6.30 \\
Northern Taiwan & 232 & \\
Central Taiwan & 45 & \\
Southern Taiwan & & \\
Eastern Taiwan & &
\end{tabular}

Table 2. ANOVA analysis of family background on attitudes

\begin{tabular}{|c|c|c|c|c|c|c|}
\hline & $\mathrm{M}$ & SD & $\mathrm{F}$ & $\mathrm{df}$ & sig & Post-hoc \\
\hline Parents' role & & & 1.05 & & & \\
\hline Father & 3.16 & 0.97 & & 2 & & \\
\hline Mother & 3.13 & 0.89 & & & & \\
\hline Others & 3.41 & 0.87 & & & & \\
\hline Parents' age & & & 1.27 & & & \\
\hline Under 29 & 3.22 & 0.74 & & 4 & & \\
\hline $30-34$ & 3.26 & 0.87 & & & & \\
\hline $35-39$ & 3.10 & 0.92 & & & & \\
\hline $40-44$ & 3.06 & 1.00 & & & & \\
\hline Over 45 & 3.15 & 0.92 & & & & \\
\hline Living region & & & 4.31 & & $*$ & $3>1.2$ \\
\hline Northern Taiwan & 3.05 & 0.98 & & 3 & & \\
\hline Central Taiwan & 3.06 & 0.87 & & & & \\
\hline Southern Taiwan & 3.32 & 0.87 & & & & \\
\hline Eastern Taiwan & 3.23 & 0.92 & & & & \\
\hline Educational background & & & 6.11 & 2 & $*$ & $1>3.0$ \\
\hline Senior or vocational high school & 3.30 & 0.87 & & & & \\
\hline University or junior college & 3.11 & 0.92 & & & & \\
\hline
\end{tabular}


Hung-Chung Lee and Mei-Ju Chou / Journal of Social Sciences 10 (1): 7-14, 2014

\begin{tabular}{|c|c|c|c|c|c|c|}
\hline Masters or higher degree & 2.93 & 1. & & & & \\
\hline \multicolumn{7}{|c|}{ Table 3. ANOVA analysis of parenting concepts on attitudes } \\
\hline & $\mathrm{M}$ & SD & $\mathrm{F}$ & df & sig & Post-hoc \\
\hline Parents' role & & & 1.092 & & & \\
\hline Father & 3.49 & 0.73 & & 2 & & \\
\hline Mother & 3.53 & 0.63 & & & & \\
\hline Others & 3.70 & 0.76 & & & & \\
\hline Parents' age & & & 0.938 & & & \\
\hline Under 29 & 3.50 & 0.68 & & 4 & & \\
\hline $30-34$ & 3.58 & 0.65 & & & & \\
\hline $35-39$ & 3.49 & 0.63 & & & & \\
\hline $40-44$ & 3.47 & 0.78 & & & & \\
\hline Over 45 & 3.59 & 0.69 & & & & \\
\hline Living region & & & 13.06 & & $*$ & $3>1.2$ \\
\hline Northern Taiwan & 3.34 & 0.70 & & 3 & & $4>1.0$ \\
\hline Central Taiwan & 3.49 & 0.62 & & & & \\
\hline Southern Taiwan & 3.68 & 0.63 & & & & \\
\hline Eastern Taiwan & 3.78 & 0.68 & & & & \\
\hline Educational background & & & 23.12 & 2 & * & $1>2.3$ \\
\hline Senior or vocational high school & 3.73 & 0.65 & & & & $2>3.0$ \\
\hline University or junior college & 3.46 & 0.64 & & & & \\
\hline Masters or higher degree & 3.23 & 0.72 & & & & \\
\hline
\end{tabular}

Table 4. Regression analysis of family background on parenting concepts

\begin{tabular}{lccc}
\hline & $\mathrm{b}$ & $\beta$ & $\mathrm{t}$ \\
\hline Parents' role & & & -0.603 \\
Mother (control group) & & & 0.415 \\
Father & -0.051 & -0.024 & 0.478 \\
Others & 0.088 & 0.016 & $-5.792 *$ \\
Parents' age & 0.018 & 0.019 & -0.216 \\
Educational background & -0.328 & & $-5.381 *$ \\
Living region & & -0.249 & -1.340 \\
Southern Taiwan (control group) & & -0.065 & 0.170 \\
Northern Taiwan & -0.522 & 0.007 & \\
Central Taiwan & -0.148 & \\
Eastern Taiwan & 0.028 & & \\
R Square & 0.112 & &
\end{tabular}

$\mathrm{p}<0.05$

Table 5. Regression analysis of family background on parenting attitudes

\begin{tabular}{|c|c|c|c|c|c|}
\hline & & \multicolumn{2}{|c|}{ Step 1} & \multicolumn{2}{|l|}{ Step 2} \\
\hline & & $\mathrm{b}$ & B & $\mathrm{B}$ & B \\
\hline \multirow[t]{5}{*}{ Role } & Mother (control group) & & & & \\
\hline & Father & 0.067 & 0.032 & 0.100 & 0.047 \\
\hline & Others & 0.319 & 0.057 & 0.264 & 0.048 \\
\hline & Age & -0.059 & -0.062 & -0.069 & -0.073 \\
\hline & Educational background & -0.161 & $-0.107 *$ & 0.018 & 0.012 \\
\hline \multirow[t]{6}{*}{ Living region } & Southern Taiwan (control group) & & & & \\
\hline & Northern Taiwan & -0.262 & $-0.150 *$ & 0.024 & 0.012 \\
\hline & Central Taiwan & -0.200 & -0.071 & -0.125 & -0.054 \\
\hline & Eastern Taiwan & -0.139 & -0.034 & -0.147 & -0.036 \\
\hline & Parenting concepts & & & 0.570 & $0.569 *$ \\
\hline & $\mathrm{R}$ square & & 0.037 & & 0.327 \\
\hline
\end{tabular}




\subsubsection{Test of Mediation}

This study uses regression analysis to verify the mediation effect of parenting concepts. From Table 4 and 5 we find the regression coefficient $\beta$ of parenting concepts is 0.569 , but it is significant, showing a partially significant effect. Therefore, the views of parents living in different regions with diverse educational background towards young children learning English at an early age are primarily mediated by their views on secular parenting concepts.

\section{DISCUSSION}

According to the purpose of our research, the research hypotheses and the empirical analysis results, the conclusions are as follows. First, parents living in central and northern Taiwan with educational backgrounds of graduate school or higher tend to disagree in their attitudes towards young children learning English at an early age as compared to parents living in southern Taiwan with high school degrees. This may be derived from the differences between the original culture and learning environments in northern and southern Taiwan. Generally speaking, people in the north have more possibilities in keeping touch with current knowledge delivery and have more possibilities in contacting foreigners or dealing with global currencies. Alternatively, people in southern Taiwan tend to have a slower pace in learning and education cultivation. Parents living in the northern region, more than in the central and southern regions tend to get their children to learn English earlier. In the parents' level of education, in general, the higher the education level, the more the attitudes of early age of learning English do not agree and is a significant gap. Next, the parents who agree with secular parenting concepts tend to agree more in their attitudes towards young children learning English at an early age. Parents who agree with the degree of secular upbringing influencing factors to affect the highest populated areas is followed by parental educational attainment. The higher the education level of parents, the parents who live in the northern region do not agree with the more secular upbringing parents which is a reaction to the general concept. Finally, the views of parents living in different regions with varying educational backgrounds towards young children learning English at an early age are primarily affected by their views on secular parenting concepts. Therefore, the perspective of parenting concepts do have significant influences in children's learning English in Taiwan.

\section{CONCLUSION}

The present study examined and showed the effects of an early start and parental socioeconomic status on young children' English proficiency. In order to compensate for the limitations of the study and to have a better understanding of the related topics, suggestions for future research are as follows.

First, this study has led to some new findings related to the sources of attitudes towards young children learning English at an early age in language learning. However, before conclusions can be summarized, it is advisable to replicate this research in other global regions. The findings from such studies could help researchers gauge the effect of parental influence on language learning attitudes. It could also be intriguing to investigate the effects of having learned English for a long time, without much progress in the level of proficiency achieved, on the attitude levels. In areas of the world where young children learn another language similar to their mother tongue, it would be worthwhile to compare their attitudes in learning this language with the experience of learning a foreign language that is more distant linguistically.

Second, the study only focused on the effects of an early start in English learning and parental SES on young children' English proficiency. There are other factors that influence the young children' English proficiency, such as the relationship between the teacher and the student, the instructor's personality and teaching methodology and so forth. For further studies, more factors influencing the young children' English proficiency should also be taken into consideration.

\section{REFERENCES}

Azmitia, E.C., 2007. Cajal and brain plasticity: Insights relevant to emerging concepts of mind. Brain Res. Rev., 55: 395-405. DOI: 10.1016/j.brainresrev.2007.01.010

Birdsong, D. and M. Molis, 2001. On the evidence for maturational constraints in second language acquisition. J. Memory Lang., 44: 235-249. DOI:10.1006/jmla.2000.2750

Bourdieu, P. and J.C. Passeron, 1990. Reproduction in Education, Society and Culture. 2nd Edn., SAGE Publications, London, ISBN-10: 0803983204, pp: 254.

Bowers, J.M., K.I. Bradley and S.M. Kennison, 2013. Hemispheric differences in the processing of words learned early versus later in childhood. J. General Psychol., 140: 174-186. DOI: 10.1080/00221309.2013.783779 
Brown, H.D., 2007. Principles of Language Learning and Teaching. 5th Edn., Longman Publishing Group, White Plains, ISBN-10: 0131991280, pp: 410.

Buchmann, C., D.J. Condron and V.J. Roscigno, 2010. Shadow education, American style: Test preparation, the SAT and college enrollment. Social Forces, 89: 435-461. DOI: 10.1080/00221309.2013.783779

Burchinal, M.R., E. Peisner-Feinberg, R. Pianta and C. Howes, 2002. Development of academic skills from preschool through second grade: Family and classroom predictors of developmental trajectories. J. School Psychol., 40: 415-436. DOI: 10.1016/S0022-4405(02)00107-3

Chang, S.J., C.J., Chang and Y.C. Lin, 2002. Investigative research on the current situation and issues of English education in kindergarten school. Elementary Educ., 42: 37-42.

Coleman, J.S., 1988. Social capital in the creation of human capital. Am. J. Sociol., 94: 95-120. DOI: $10.2307 / 2780243$

Coleman, J.S., E. Campbell, C. McPartiand, F. Mood and F. Weinfeld et al., 1966. Equality of educational opportunity. National Center for Educational Statistics, Department of Health, Education and Welfare. Washington, D.C.

De Graaf, P.M., 1986. The impact of financial and cultural resources on educational attainment in the Netherlands. Sociol. Educ., 59: 237-246. DOI:10.2307/2112350

Farkas, G., R.P. Grobe, D. Sheehan and Y. Shuan, 1990. Cultural resources and school success. Am. Sociol. Rev., 55: 127-142.

Guiora, A., B. Beit-Hallahm, R. Branon, C. Dull and T. Scovel, 1972. The effects of experimentally induced changes in ego states on pronunciation ability in second language: An exploratory study. Comprehension Psychiatry, 13: 139-150. DOI: 10.1016/0010-440X(72)90083-1

Heinesen, E. and B.K. Graversen, 2005. The effect of school resources on educational attainment: Evidence from Denmark. Bull. Econ. Res., 57: 109143. DOI: $10.1111 / \mathrm{j} .0307-3378.2005 .00217 . x$

Henderson, A.T. and N. Berla, 1994. A New Generation of Evidence: The Family is Critical to Student Achievement. 1st Edn., Center for Law and Education, Washington, DC., ISBN-10: 0934460418, pp: 160.

Hwang, Y.J., 1997. Occupation, education, the parental value and behavior modes: Arguing against the fitness of Kohn's theory in Taiwan. J. Nat. Taitung Teachers College, 8: 1-26.

Jhong, Y.J., 2009. The relationship between parenting beliefs and parents' participation in early childhood. J. Family Educ. Counsel., 6: 35-57.
Kau, S.K., 1991. Sociology of Family. Li-Ming, Taipei.

Kuo, Y., 2002. The Effects of Age on Taiwanese EFL Learners' Long-Term English Proficiency. 1st Edn,. University of Kansas, pp: 428.

Mayberry, R., J.K. Chen, P. Witcher and D. Klein, 2011. Age of acquisition effects on the functional organization of language in the adult brain. Brain Lang., 119: 16-29. DOI: 10.1016/j.bandl.2011.05.007

McGillicuddy-DeLisi, A.V., 1982. Parents' beliefs about developmental processes. Human Dev., 25: 192-200. DOI: $10.1159 / 000272796$

Molfese, V.J., K.M. Rudasill, J.L. Beswick, J.L. JacobiVessels and M.C. Ferguson et al., 2010. Infant temperament, maternal personality and parenting stress as contributors to infant developmental outcomes. Merrill-Palmer Q., 56: 47-79. DOI:10.1353/mpq.0.0039

Robinson, K. and A.L. Harris, 2013. Racial and social class differences in how parents respond to inadequate achievement: Consequences for children's future achievement. Soc. Sci. Q., 94: 1346-1371. DOI: 10.1111/ssqu.12007

Rodriguez, A. and K. Adamsons, 2012. Parenting expectations: Younger and older first-time parents. Marriage Family Rev., 48: 248-271. DOI: 10.1080/01494929.2012.665014

Sigel, I.E. and McGillicuddy-DeLisi. 2005. Parental Beliefs are Cognitions: The Dynamic Belief Systems Model. In: Handbook of parenting 3, Bornstein, M.H. (Ed.), Lawrence Erlbaum Associates, Mahwah, New Jersey, ISBN-10: 0805837809, pp: 485-508.

Snow, C.E. and M. Hoefnagel-Hohle, 1978. Age Difference in Second Language Acquisition. In: Second language Acquisition: A Book of Reading, Hatch, E.M. (Ed.), Newbury House, Rowley, MA., ISBN-10: 0883770865, pp: 333-344.

Teachman, J.D., 1987. Family background, educational resources and educational attainment. Am. Sociol. Rev., 52: 548-557.

Tsai, C.H., 2001. Parents' attitudes towards English learning for their kindergarten children. MSc Thesis, Nanhua University, Chiayi, Taiwan.

Wang, L. and H. Chang, 2011. Improve oral training: The method of innovation assessment on English speaking performance. Int. J. Distance Educ. Technol., 9: 56-72. DOI: 10.4018/jdet.2011070105

Wei, M.H. and C.C. Yang, 2010. A study on factors influencing parents' rearing attitudes in central part of Taiwan. J. Educ. Nat. Changhua Univ. Educ., 18: 65-93.

Yan, J.X. and C. Detaramani, 2008. A comparison of language anxiety in English and mandarin learning in Hong Kong. English Teach. Learn., 32: 45-85. 